\title{
Gas gangrene panophthalmitis treated with hyperbaric oxygen
}

\author{
J. H. BRISTOW, B. KASSAR, AND D. SEVEL \\ Department of Ophthalmology, Groote Schuur Hospital $\mathcal{E}$ University of Cape Town, South Africa
}

Gas gangrene panophthalmitis is a rare and serious complication of penetrating injury of the eye. Since 1904, 6r cases have been described in the literature (Leavelle, I955; Arnold, I955; Oehring and Jütte, I963; Walsh, I965; McEntyre and Curran, I968; Kurz and Weiss, I969).

A further patient is now reported as this is the first documented case in which hyperbaric oxygen was used as an adjuvant to therapy.

\section{Case report}

A ro-year-old boy came to the Eye Department of Groote Schuur Hospital on January 6, 1970, with a painful left eye. He had been making a fowl-run in a rather dirty and dusty back-yard 18 hours previously and, while hammering a nail, had suddenly experienced a sharp pain in the left eye. Immediately after the injury he had little pain, but that night the eye became painful, and within 12 hours there was swelling of the lids and a discharge from the eye.

\section{Examination}

The visual acuity of the left eye was only perception of light. There was severe lid oedema (Fig. I) and conjunctival chemosis associated with some degree of global tenderness. A 4-mm. perforating wound in the cornea was covered by a brownish muco-pus (Fig. 2).
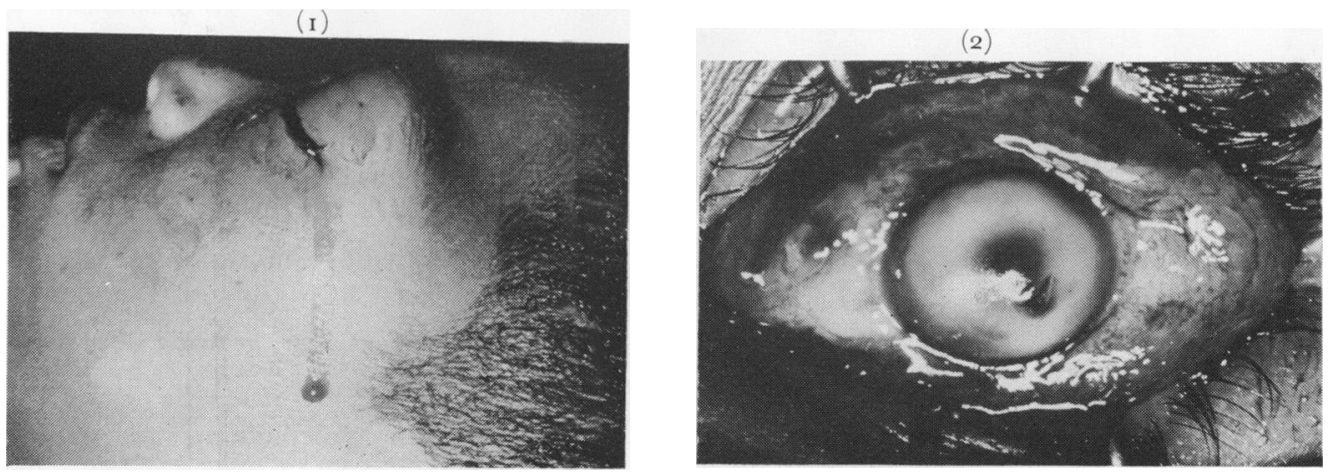

FIG. I Swelling of periorbital region as well as over the temporal fossa region. A brownish muco-pus is trickling over the skin.

FIG. 2 4-mm. perforating wound of the cornea is covered by muco-pus. 
The anterior chamber was shallow and the iris leaf was not clearly seen as it was obscured by hypopyon and gas bubbles. There was no red reflex on fundoscopy. Ocular movements were full in all directions of gaze. $X$ ray of the orbits demonstrated a radio-opaque intraocular foreign body lying posteriorly in the globe (Fig. 3). While the swab was being taken for bacteriological examination a sweetish-smelling gas escaped from the corneal wound with an audible hiss.

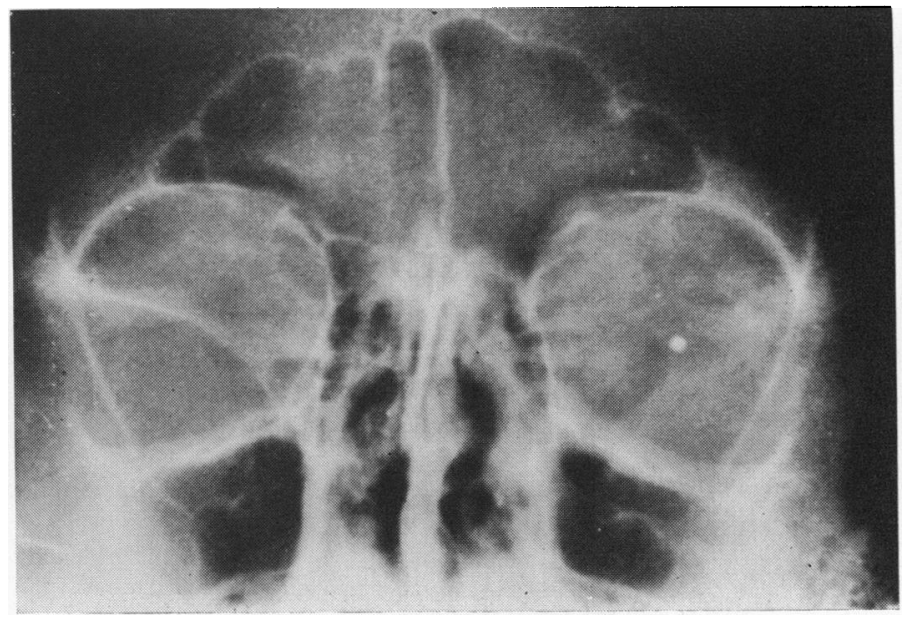

FI G. $3 X$ ray of orbit, showing intraocular radio-opaque foreign body

\section{Bacteriological examination}

The exudate showed scanty Gram-positive bacilli, morphologically compatible with a clostridial species (Fig. 4).

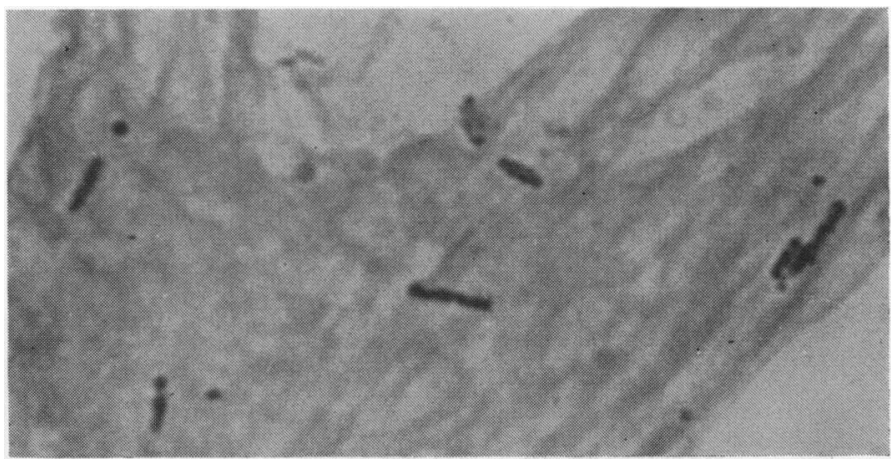

FIG. 4 Rod-shaped Clostridium welchii bacilli. Gram stain. $\times 700$

On culture a scanty but pure growth of a Gram-positive bacillus was obtained with the following characteristics:

(I) Smooth rounded $\beta$-haemolytic colonies on horse-blood agar, growing only anaerobically.

(2) The production of a "stormy clot" in litmus milk medium.

(3) Inoculation of the organisms onto a lecithin-containing medium and anaerobic culture showed the presence of lecithinase activity, which was neutralized by Clostridium welchii alpha antitoxin. In addition a growth of Staphylococcus aureus was obtained from another swab.

The right eye showed no pathology and the visual acuity was $6 / 6$.

The child's general condition was unsatisfactory; he was drowsy and apathetic, the temperature was $102 \cdot 2^{\circ} \mathrm{F}$, and the pulse $102 / \mathrm{min}$. Terminal neck stiffness was present. Lumbar puncture 
revealed a pressure of $120 \mathrm{~mm}$. $\mathrm{H}^{2} \mathrm{O}$, the protein was $10 \mathrm{mg}$. per cent. and the glucose was within normal limits using the Dextrostix. The cerebrospinal fluid was clear and there were no cells on microscopical examination.

A full blood count showed haemoglobin $13.3 \mathrm{~g}$. per cent., total white cell count 6,800 per cu. mm. (neutrophils 52 per cent., eosinophils 7 per cent., lymphocytes 33 per cent.).

Diagnosis

Gas gangrene panophthalmitis was diagnosed and therapy was immediately commenced.

\section{Treatment}

Intravenous penicillin $20,000,000 \mathrm{u}$ per $\mathrm{I}, 000 \mathrm{ml}$. normal saline was administered over the first 24-hour period. In addition $1 \mathrm{ml}$. formol tetanus toxoid was given intramuscularly. Within 18 hours of starting therapy the patient's condition deteriorated. There was a marked increase in the lid swelling which extended laterally into the temporal fossa. The conjunctival chemosis increased considerably. The hypopyon level rose and the iris could not be seen. Although the temperature had dropped to $100^{\circ} \mathrm{F}$. and the pulse rate to $100 / \mathrm{min}$., the child was more apathetic and toxic. An Astrup examination revealed a satisfactory acid-base relationship: viz. ph. $7 \cdot 42$ base excess $+3 \cdot 6$. The urinary output during the first 20 hours of hospitalization was $900 \mathrm{ml}$.

In view of the ocular and systemic deterioration on antibiotic therapy alone, the patient was taken to the operating theatre and on January 7, 1970, the left eye was eviscerated. The globe contained necrotic tissue and haemolysed blood. No intraocular elements were recognizable macroscopically. A $2 \times 3 \mathrm{~mm}$. metallic foreign body was recovered from within the globe.

Because of the marked oedema of the orbital tissue, and the conspicuous swelling of the lids and temporal region, orbital and extraorbital extension of the gas gangrene was suspected, and on January 7, 1970, hyperbaric oxygen therapy was commenced. The patient was treated in a singlepatient transparent hyperbaric oxygen chamber filled and ventilated with roo per cent. oxygen at a pressure of 3 atmospheres absolute, i.e. $29.4 \mathrm{lb}$./sq. in. During the 30 hours after evisceration he spent six 2-hour periods in the oxygen chamber. The intravenous penicillin therapy was continued for 5 days postoperatively and from the first postoperative day $40 \mathrm{mg}$. gentamycin was given intramuscularly twice daily.

48 hours after starting the hyperbaric oxygen treatment, there was systemic improvement. The temperature and pulse rate settled to normal levels and the patient became alert and interested in his surroundings. By the $4^{\text {th }}$ postoperative day the periorbital swelling and tenderness had completely subsided and there was minimal discharge from the socket.

Result

The subsequent course was uneventful and the patient was discharged on January 16, 1970. A prosthesis was fitted 6 weeks after the operation.

\section{Discussion}

Panophthalmitis following the entry of an intraocular foreign body is rarely complicated by gas gangrene. The distinctive characteristics of gas gangrene panophthalmitis are marked lid swelling, severe conjunctival chemosis, and a coffee-coloured discharge from the eye, the last being a constant finding. In addition, hypopyon and gas in the anterior chamber may be observed. Gas in the anterior chamber has not always been noted in the previous cases described. Numerous swabs should be taken and the laboratory specifically requested to look for Clostridium welchii bacilli.

In the previous cases described, the infection has been controlled by antibiotic therapy and either evisceration or enucleation. No eye with proven gas gangrene panophthalmitis has ever been saved by antibiotic therapy alone. 
Leavelle (1955), in his review of 55 cases, reported two patients who required exenteration of the orbit. One of these had an enucleation as a primary procedure, but this failed to control the infection as there was evidence of extraocular spread of the infection. The other case required exenteration as a primary procedure.

Slack, Hanson, and Chew (1969) maintained that hyperbaric oxygen, by reducing toxaemia and arresting futher spread of the disease, re-established the state in which antibiotic

therapy and debridement can once more be effective. Hyperbaric oxygen does not kill Clostridium welchii organisms, but inhibits their growth. It is doubtful whether hyperbaric oxygen has in fact any effect on the avascular cornea, lens, and vitreous. Furthermore, $\stackrel{\mathbb{D}}{\AA}$ ocular blood vessels like those of the brain constrict in the presence of increased oxygen क tension (Saltzman, Anderson, Hart, Duffy, and Sieker, I965; Brummelkamp, 1965). $\vec{\circ}$ Hyperbaric oxygen was used in this case because there was the possibility that the gas gangrene had extended beyond the eye to involve the orbital and surrounding tissue.

Intensive antibiotic therapy with evisceration or enucleation is the treatment of choice $\frac{0}{0}$. with gas gangrene panophthalmitis. Hyperbaric oxygen is indicated only when there is clinical evidence of extraocular extension of the gas gangrene.

The bacteriological examination was carried out by Dr. A. Forder of the Department of Bacteriology, Groote Schuur Hospital.

The investigation was financed by the Gratitude Fund of Ophthalmology and the Goosen Fund, University of Cape Town.

\section{References}

ARNOLD, E. L. (1955) Trans. ophthal. Soc. U.K., 75, 259

BRUmmelkamp, w. H. (1965) In "Hyperbaric Oxygenation, Proc. 2nd int. Congr., Glasgow, I9640

ed. I. McA. Ledingham, p. 239. Livingstone, Edinburgh

KURZ, G. H., and WEISS, J. F. (1969) Brit. F. Ophthal., 53, 323

LeAvelle, R. B. (1955) A.M.A. Arch. Ophthal., 53, 634

McEnTYre, J. M., and Curran, K. E. (ig68) Amer. J. Ophthal., 65, 109

OEHRING, H., and JÜtTE, A. (1963) Dtsch. med. Wschr., 88, 2092

SAltzman, A., ANDERSON, B., HART, L., DUfFy, E., and sieker, H. O. (1965) In "Hyperbaric Oxy-

genation, Proc. 2nd int. Congr., Glasgow, 1964", ed. I. McA. Ledingham, p. 202. Livingstone, Edinburgh

SLACK. W. K., hanson, G. C., and chew, H. E. R. (1969) Brit. F. Surg., 56, 505 